\title{
Protocol
}

\section{Trial design and protocol of randomized controlled trial comparing the efficacy of oral mefenamic acid, paracetamol and placebo for analgesic prophylaxis in childhood vaccination (MAP VaC trial)}

\author{
Rachna Pasi $^{1 *}$, Thirunavukkarasu Arun Babu', Vinoth Kumar Kallidoss ${ }^{2}$
}

\begin{abstract}
${ }^{1}$ Department of Pediatrics, ${ }^{2}$ Department of Community and Family Medicine, All India Institute of Medical Sciences (AIIMS), Mangalagiri, Andhra Pradesh, India
\end{abstract}

Received: 17 May 2021

Revised: 08 July 2021

Accepted: 09 July 2021

\author{
*Correspondence: \\ Dr. Rachna Pasi, \\ E-mail: rachna.pasi@gmail.com
}

Copyright: ( $)$ the author(s), publisher and licensee Medip Academy. This is an open-access article distributed under the terms of the Creative Commons Attribution Non-Commercial License, which permits unrestricted non-commercial use, distribution, and reproduction in any medium, provided the original work is properly cited.

\begin{abstract}
Background: Needle related pain has been one of the most important concerns for parents of children receiving vaccination. Non-steroidal anti-inflammatory drugs (NSAIDs) like paracetamol and mefenamic acid have been commonly used as analgesics in pediatric population. However, prophylactic administration of these drugs for analgesia during vaccination has not been studied. The main objective of this study is to compare the efficacy of prophylactic paracetamol, mefenamic acid and placebo on needle pain associated with vaccination.

Methods: This is a three-arm parallel, triple blind, randomized controlled trial. Children aged 6 weeks to 7 years who need immunization as per national immunization schedule and reporting to pediatric outpatient department (OPD) at tertiary level hospital, AIIMS Mangalagiri, Andhra Pradesh, will be included. All participants will be randomly allotted to any of the three groups by computer based block randomization. Each participant will be given any one of the three drugs as per their allocation. Vaccination will be done as per national immunization schedule after 30 minutes of drug administration. Face, legs, activity, cry, consolability (FLACC) scoring will be done immediately after vaccine administration and repeated at 15 minutes and 30 minutes. All personnel involved in randomization, drug and vaccine administration, FLACC scoring and statistical analysis will be blinded along with parents and children enrolled in the study.

Conclusions: If this intervention study shows evidence of a difference between drug and placebo signifying reduction in vaccine related pain with these drugs, this will have a huge impact on National Immunization programme by improving compliance, vaccine coverage and by reducing vaccine hesitancy.

Trial registration: Clinical trials registration number is CTRI/2021/01/030239.
\end{abstract}

Keywords: Immunization, Needle pain, FLACC scoring, Analgesics

\section{INTRODUCTION}

Immunization plays a crucial part in preventing common childhood infections and has a long-term positive impact on the health of children. For parents and children, Immunization is associated with fear of getting vaccinated due to needle associated pain. Pain is an unpleasant experience at any age, but is often underestimated in pediatric population. This may be due to lack of awareness or difficulty in quantifying pain in children. According to the International Association for the study of pain, "pain is an unpleasant sensory and emotional experience associated with actual or potential tissue damage". Perception of pain in children is complex, and entails physiological, psychological, behavioral, and developmental factors. ${ }^{1}$ However, in spite of common occurrence, pain in infants, children, and adolescent is often under-diagnosed and under-treated. ${ }^{2}$ It has also been 
shown that infants and children, who experience pain in early life, have long-term abnormal pain perception and negative neurobehavioral outcomes. ${ }^{2}$ Managing pain in infants and children presents a unique challenge that necessitates consideration of their age, developmental level, cognitive and communication skills, previous pain experiences, and associated social beliefs. ${ }^{3}$

Paracetamol and mefenamic acid are non-steroidal antiinflammatory drugs (NSAIDs) commonly used as analgesics in pediatric population for acute pain. ${ }^{4}$ NSAIDs act by reversibly inhibiting enzyme cyclooxygenase which converts arachidonic acid to prostaglandins (PGs), prostacyclins and thromboxanes. ${ }^{5}$ PGs play an important role in inflammatory and nociceptive processes, in addition to their role in other physiological functions such as maintenance of the gastric mucosal barrier, regulation of renal blood flow, and regulation of endothelial tone. Among NSAIDs, paracetamol and mefenamic acid have been used in post-exposure management of pain and fever in vaccinated children. Both drugs have been widely used as anti-pyretic, analgesics and anti-inflammatory drug in children. Paracetamol has been widely used in children for many decades more commonly than mefenamic acid. Mefenamic acid is used effectively in acute pain management in many studies as a single dose, like post orthopedic surgeries, dental procedures and episiotomies. ${ }^{6}$ Mefenamic acid is also used to relieve symptoms of inflammation, pain and discomfort caused by arthritis, muscular or rheumatic disorders, headache or toothache, pain after operations, trauma, fever in children and dysmenorrhea in girls. Mefenamic acid is rapidly absorbed after oral administration. Peak plasma levels are attained in 2 to 4 hours and the elimination half-life is approximately 2 hours. ${ }^{6}$ Several studies have proved that mefenamic acid is effective and safe drug for closure of patent ductus arteriosus in premature newborn babies. ${ }^{7,8}$

\section{Objectives of the study}

Primary objective was to assess the effect of mefenamic acid or paracetamol as prophylactic analgesic in pain management in children during vaccination using face, legs, activity, cry, consolability (FLACC) scale.

Secondary objective was to assess the effect of mefenamic acid or paracetamol on systemic symptoms (fever) after vaccination.

\section{METHODS}

\section{Trial design}

It is a prospective, triple blind, three arm parallel, randomized placebo controlled trial.

\section{Study setting}

The study will be conducted at pediatrics department of a tertiary level care institute, All India Institute of Medical
Sciences (AIIMS) Mangalagiri, one of the institutes of national importance located in southern part of India.

\section{Eligibility criteria}

\section{Study population}

Children aged 6 weeks to 7 years who will be coming to outpatient department of AIIMS Mangalagiri for vaccination.

\section{Inclusion criteria}

Children who will be coming for routine vaccination as per national immunization schedule (NIS) and whose parents will give written informed consent to participate in this study.

\section{Exclusion criteria}

Children with any liver or kidney diseases, coagulation disorders, past history of any allergic reactions and in whom pain assessment cannot be satisfactorily done will be excluded from the study.

\section{Sample size}

The previous studies done in India showed that mean (SD) FLACC score after immunization was 6.2 (1.14). ${ }^{9}$ Expecting at least $15 \%$ reduction in FLACC score with 5\% alpha error and $80 \%$ power using Open-Epi software version 3.01, the sample size was calculated to be 24 in each group, anticipating a $20 \%$ lost to follow up, the final sample size was rounded off to 30 in each group.

\section{Ethical consideration}

This three arms, triple-blinded, randomized controlled trial study was registered in clinical trial registry of India after obtaining approval from the institute ethical committee (IEC Approval number: AIIMS/MG//IEC/2020-21/78). Trial registration number: CTRI/2021/01/030239.

\section{Randomization and group assignment}

\section{Randomization}

Block randomization will be done through computer automatic randomization table generation. Sequence generation will be done through randomization software.

\section{Allocation concealment mechanism}

The list generated through software will be kept in opaque, concealed envelopes. Sealed envelopes containing the group allocation coded as $\mathrm{A}, \mathrm{B}$ and $\mathrm{C}$ will be made for randomly allocating participants. Children will be assigned to three groups according to allocation and will receive mefenamic acid, paracetamol or placebo accordingly. The physical characteristics of placebo and both drugs will be matched (Table 1). 
Table 1: Comparison of physical characteristics of drugs and placebo.

\begin{tabular}{|llll|}
\hline $\begin{array}{l}\text { Characteris } \\
\text {-tics }\end{array}$ & $\begin{array}{l}\text { Paraceta- } \\
\text { mol }\end{array}$ & $\begin{array}{l}\text { Mefenamic } \\
\text { acid }\end{array}$ & Placebo \\
\hline Colour & $\begin{array}{l}\text { Sunset } \\
\text { yellow }\end{array}$ & $\begin{array}{l}\text { Sunset } \\
\text { yellow }\end{array}$ & $\begin{array}{l}\text { Sunset } \\
\text { yellow }\end{array}$ \\
\hline State & Liquid & Liquid & Liquid \\
\hline Flavor & Mango & Mango & Mango \\
\hline Consistency & Thin & Thin & Thin \\
\hline
\end{tabular}

\section{Blinding}

The personnel involved in administering drug, vaccination and statistician will not know the group allocation and drug administered to the participant, including parents and children. The personnel involved in performing FLACC scoring for participants during and after vaccination will also be blinded about the nature of drug administered. Concealment will be disclosed only after statistical analysis is performed and results are locked.

\section{Implementation}

Written informed consent will be taken from the parents/legal guardian before enrollment. Envelopes will be opened sequentially and group allocation to any one of the three groups will be done as per coding inside the envelope. Every enrolled child will receive one drug labeled either $\mathrm{A}$ or $\mathrm{B}$ or $\mathrm{C}$ as per their allocation and dosage given below.

\section{Dose and concentration of paracetamol}

Concentration of syrup paracetamol used in the study is $250 \mathrm{mg} / 5 \mathrm{ml}$ and dose is $10 \mathrm{mg} / \mathrm{kg} / \mathrm{dose}$. Single dose will be given 30 minutes before vaccination.

\section{Dose and concentration of mefenamic acid}

Concentration of syrup mefenamic acid used in study is $100 \mathrm{mg} / 5 \mathrm{ml}$ and dose is $4 \mathrm{mg} / \mathrm{kg} / \mathrm{dose}$. Single dose will be given 30 minutes before vaccination.

\section{Placebo}

Mango flavored, sunset yellow solution in used. Dose as per weight band (Table 2). Single dose will be given 30 minutes before vaccination.

The following weight bands will be used to administer drugs.

After drug administration, children will wait for 30 minutes before getting vaccination. FLACC scoring will be done first at the time of vaccination, followed by subsequent scoring at 15 and 30 minutes respectively. All FLACC scorings will be done independently by a trained professional who is not involved in vaccination process.

\section{Study tool}

The FLACC has five parameters to be assessed which are face, legs, activity, cry and consolability. Each of these parameters are ranked on three-point scale (0-2) as per response severity as described under each parameter. Together all scores add up to 0-10. It is easy to administer this scale for post-procedural pain measurement in children from 2 months to 7 years of age. ${ }^{10}$ It is a reliable and valid scale used in many studies involving children. ${ }^{11}$

\section{Study outcomes}

Outcomes will be measured in terms of change in total FLACC scoring done during vaccination, 15 minutes and 30 minutes after vaccination. Parents will be asked to follow up after 24 hours either physically or via teleconsultation to know about systemic symptoms like appearance of fever after vaccination, grade of fever and when the child need further dose of anti-pyretic after vaccination.

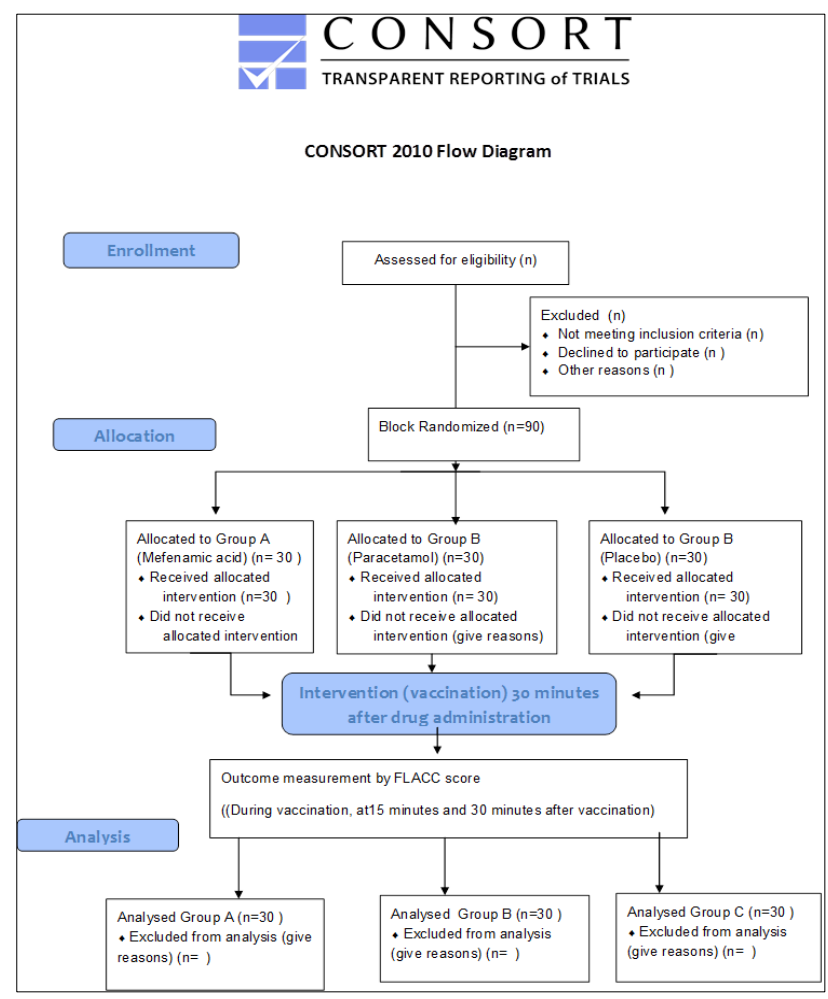

Figure 1: Participants flow diagram.

\section{Statistical analysis}

Data entry and analysis will be done using Epi-info (version 7.2.4) and R-software (version 3.6). Continues variables like age, FLACC score will be summarized as mean and standard deviation and categorical variables like gender, study group will be summarized as frequency and percentage.

The association between continues variables and categorical variables will be analyzed using analysis of 
variance (ANOVA). The change in FLACC scoring over the time of observation will be analyzed by repeated measure ANOVA. The association between categorical variables will be analyzed using Chi-square test. Intention to treat analysis method will be used. A p value $<0.05$ will be considered as statistically significant.

Table 2: Weight band for drug A, B and drug C.

\begin{tabular}{|lll|}
\hline SI. no. & $\begin{array}{l}\text { Weight of the child } \\
(\mathbf{k g})\end{array}$ & $\begin{array}{l}\text { Dose drug } \mathrm{A} / \mathrm{B} / \mathrm{C} \\
(\mathbf{m l})\end{array}$ \\
\hline $\mathbf{1}$ & $3-5$ & 1 \\
\hline $\mathbf{2}$ & $6-10$ & 2 \\
\hline $\mathbf{3}$ & $11-15$ & 3 \\
\hline $\mathbf{4}$ & $16-20$ & 4 \\
\hline $\mathbf{5}$ & $21-25$ & 5 \\
\hline $\mathbf{6}$ & $26-30$ & 6 \\
\hline $\mathbf{7}$ & $31-35$ & 7 \\
\hline
\end{tabular}

\section{DISCUSSION}

Vaccination is most common painful procedure done to all normal healthy children at multiple times starting from birth to adolescence. As per 2009 health styles survey, the vaccine-related concerns listed most often by parents were pain $(44.2 \%)$, followed by child getting too many vaccines $(34.2 \%) .{ }^{12}$ Although, mefenamic acid and other NASIDs like paracetamol are very frequently prescribed as analgesic and anti-pyretic following vaccination, there are no published studies for use of mefenamic acid or paracetamol as prophylactic analgesic for procedural pain before vaccination. So, this study is planned to find out role of mefenamic acid and paracetamol as prophylaxis for needle associated pain during vaccination. This study will provide evidence for using mefenamic acid or paracetamol as prophylactic analgesic during vaccination. This intervention can reduce needle fear in children and apprehension among parents. It will also indirectly improve vaccine compliance and overall vaccination coverage.

\section{Strength}

This study addresses the most common issue related to vaccination i.e. needle pain. The study has novelty as no other published studies have looked into 'prophylactic analgesia' for vaccine related pain using mefenamic acid and paracetomol. Since this is a randomized controlled, triple blind trial, results will be unbiased. If this study shows any evidence to use prophylactic analgesics, that can make vaccination less painful, more tolerable to children.

\section{Limitation}

This is a single center-based study. Similar large scale, multicentric studies are needed before this study findings can be generalized to other populations.

\section{CONCLUSION}

This study is planned to know the effect of analgesic prophylaxis on needle pain during vaccination. If this study shows a significant reduction in pain associated with vaccination, then it will definitely have a great impact on National Immunization Program. This intervention will not only increase acceptance of vaccine for both parents and children but also alleviate their anxiety and fear of needle prick. This intervention also has the potential to reduce 'vaccine hesitancy' and to increase overall vaccine coverage.

\section{Funding: No funding sources \\ Conflict of interest: None declared}

Ethical approval: The study was approved by the Institutional Ethics Committee and trial has been registered at central trial registry of India, CTRI

\section{REFERENCES}

1. Morton NS. Pain assessment in children. Paediatr Anaesth. 1997;7(4):267-72.

2. McGrath PJ, Frager G. Psychological barriers to optimal pain management in infants and children. Clin J Pain. 1996;12(2):135-41.

3. Srouji R, Ratnapalan S, Schneeweiss S. Pain in Children: Assessment and Nonpharmacological Management. Int J Pediatr. 2010;474838.

4. Moore RA, Edwards J, Barden J, McQuay HJ. Bandolier's LittleBook of Pain. Oxford: Oxford University Press, 2003.

5. FitzGerald GA, Patrono C. The coxibs, selective inhibitors of cyclooxygenase-2. N Engl J Med. 2001;345(6):433-42.

6. Moll R, Derry S, Moore RA, McQuay HJ. Single dose oral mefenamic acid for acute postoperative pain in adults. Cochrane Database of Systematic Rev. 2011;3:CD007553.

7. Lee JJ, Lee YH, Shin SM. Treatment of PDA in premature newborns with mefenamic acid. Yeungnam University Journal of Medicine. 1993;10(2):506-11.

8. Park HJ, Jung YS, Kim NS, Kim CR, Kim H, Moon S. A Comparative Study of the Effects of Intravenous Indomethacin and Oral Mefenamic Acid in the Treatment of Premature Infants with Patent Ductus Arteriosus. J Korean Pediatr Soc. 2001;44:32-9.

9. Gedam DS, Verma M, Patil U, Gedam S. Effect of Distraction Technique During Immunization to Reduce Behaviour Response Score (FLACC) to Pain in Toddlers. J Nepal Paediatr Soc. 2013;33(1):25-30.

10. Merkel SI, Voepel-Lewis T, Shayevitz JR, Malviya S. The FLACC: a behavioral scale for scoring postoperative pain in young children. Pediatr Nurs. 1997;23(3):293-7.

11. Merkel S, Voepel-Lewis T, Malviya S. Pain assessment in infants and young children: the FLACC scalex. Am J Nurs. 2002;102(10):55-68. 
12. Kennedy A, Basket M, Sheedy K. Vaccine attitudes, concerns, and information sources reported by parents of young children: results from the 2009 HealthStyles survey. Pediatrics. 2011;127(1):92-9.
Cite this article as: Pasi R, Arun Babu T, Kallidoss VK. Trial design and protocol of randomized controlled trial comparing the efficacy of oral mefenamic acid, paracetamol and placebo for analgesic prophylaxis in childhood vaccination (MAP VaC trial). Int J Clin Trials 2021;8(3):218-22. 